\title{
Prevalence and outcome of hypothyroidism in women attending antenatal clinic at J. J. M Medical College
}

\author{
Sapna I. S., Zainab Mehazeena*
}

Department of Obstetrics and Gynecology, J. J. M Medical College, Davangere, Karnataka, India

Received: 01 June 2017

Accepted: 27 June 2017

\section{*Correspondence:}

Dr. Zainab Mehazeena,

E-mail: zainabmehazeena@gmail.com

Copyright: (C) the author(s), publisher and licensee Medip Academy. This is an open-access article distributed under the terms of the Creative Commons Attribution Non-Commercial License, which permits unrestricted non-commercial use, distribution, and reproduction in any medium, provided the original work is properly cited.

\begin{abstract}
Background: Pregnancy induces physiological and metabolic changes, when overlapped with endocrine imbalance leads to undesirable consequences for both mother and fetus. Thyroid pathology has major negative impact on both mother and fetus. Hypothyroidism may be pre-existent or may begin during pregnancy; severity depends on how early and appropriately treatment is initiated. Aim of this study is to evaluate the prevalence of hypothyroidism in pregnancy and its outcome.

Methods: 150 pregnant women obstetric files were studied based on their TSH value, women with TSH levels greater than $3 \mathrm{mIU} / \mathrm{ml}$ who were on L-Thyroxin were included. All others who had diabetes, collagen disease, heart disease with pregnancy were excluded from the study.

Results: Prevalence of hypothyroidism in pregnancy is $1.2 \%$.

Conclusions: Hypothyroidism presents with complex and serious complications with increase in maternal morbidity and perinatal mortality. To identify potential and overt hypothyroid patient thyroid screening is must during pregnancy. TSH levels should be kept less than $2 \mathrm{mIU} / \mathrm{L}$ for adequate control.
\end{abstract}

Keywords: Hypothyroidism, Maternal morbidity, Perinatal mortality, Pregnancy

\section{INTRODUCTION}

In pregnancy, many physiological changes occur including cardiovascular, hematological, metabolic, renal, respiratory and hormonal. Thyroid function is very intimately related with reproductive performance in women. ${ }^{1}$ Thyroid gland which secrete hormones regulate metabolism and hormone production needed for cellular oxidation and neurophysiologic development. ${ }^{2}$

In pregnancy, there is increase in demand on maternal thyroid hormones, which bring about changes in thyroid stimulating hormone, thyroid binding globulin, and total thyroid hormone levels. ${ }^{3}$

Hypothyroidism in pregnancy may lead from subclinical symptom to pregnancy related complications like abortion, abruption, and pre-eclampsia, gestational hypertension, preterm labor, and low birth infants, late fetal deaths leading to increase maternal morbidity, perinatal morbidity and mortality. ${ }^{2}$ Prevalence of hypothyroidism in pregnancy is $2.5 \%{ }^{4}$

Objective of present study was to know prevalence of hypothyroidism and its outcome in pregnant women attending hospital attached to J. J. M. Medical College, Davangere.

\section{METHODS}

The obstetric files of pregnant women with hypothyroidism who delivered at J. J. M. Medical college hospital between 18-35yrs of age during the period from January 2015 to December 2015. 


\section{Inclusion criteria}

Pregnant women with TSH levels greater than $3 \mathrm{mIU} / \mathrm{L}$ who were on L-Thyroxin and not were included.

\section{Exclusion criteria}

Pregnant women who were on drugs like iodine, lithium, amiodarone.

Other associated diseases like diabetes mellitus, collagen disease and heart diseases. Multiple pregnancy, Molar pregnancy and Ectopic pregnancy.

It is a retrospective cohort study of 150 booked pregnant women with hypothyroidism, who delivered in hospitals attached to JJM Medical College. Obstetric files were studied, triiodothyronine, thyroxine, thyroid stimulating hormone were noted. Patients with TSH greater than $3 \mathrm{mIU} /$ litre were started on Tablet L-Thyroxine. Dose of L-thyroxine was adjusted to keep TSH level between 0.2$3 \mathrm{mIU} /$ litre. Various obstetrical complications were noted.

\section{RESULTS}

There were total 12,300 deliveries in the year 2015 (January $1^{\text {st }}$-December $31^{\text {st }}$ ) in the hospitals attached to $\mathrm{J}$. J. M. Medical College, and 150 pregnant women were diagnosed with hypothyroidism. Prevalence of hypothyroidism in pregnancy is $1.2 \%$. Out of 150 cases, 86 were primigravida and 64 were multigravida. Mean age at presentation was 28.4 years. 72 patients did not have any complications, whereas 78 patients had various complications.

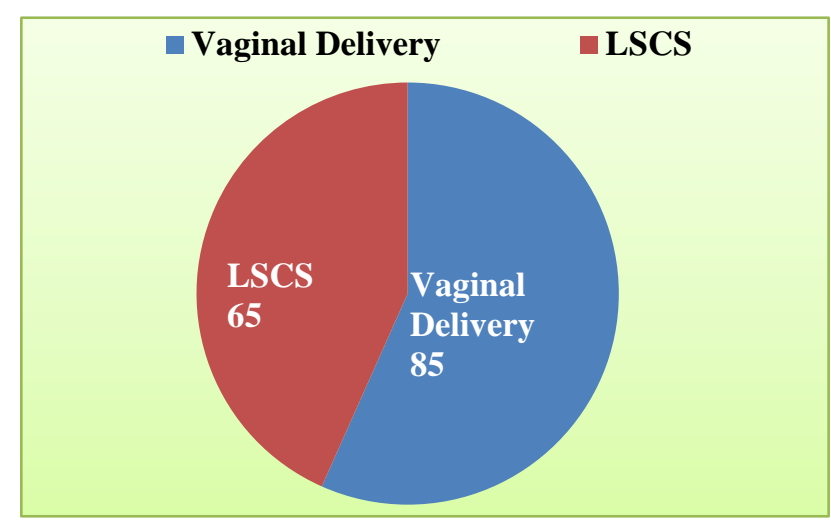

Figure 1: Mode of delivery.

Various obstetrical complications are as follows .32 women $(21.3 \%)$ had previous history of abortions, 25 patients $(16.6 \%)$ had preterm delivery, 20 women (13.3\%) had preeclampsia, 6 women (4\%) had PROM, 5 patients $(3.3 \%)$ had gestational diabetes mellitus, 2 patients $(1.3 \%)$ came with term intrauterine death, 5 patients $(3.3 \%)$ had intrauterine growth restriction and 2 patients $(1.3 \%)$ had postpartum hemorrhage which was managed medically.

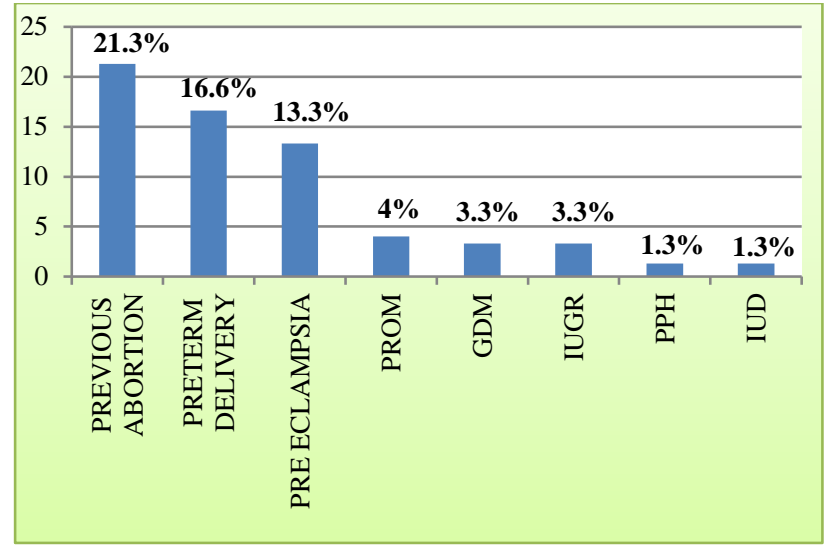

Among 150 deliveries, 85 women hadvaginal delivery and the remaining 65 underwent lower segment caesarean section. Major indication being precious pregnancy (35\%). Other indications were fetal distress (25\%), severe pre-eclampsia with unfavorable cervix (10\%), failure to progress due to minor degree CPD (10\%).

\section{DISCUSSION}

Pregnancy induces stress on maternal thyroid gland due to various factors, increase in Thyroxine binding globulin, increased demand for iodine and thyroid stimulation by HCG. $^{5}$ It is borderline hypothyroid women, who conceive and become subclinical or overt hypothyroid during pregnancy. During first 12 weeks fetus depends on mother for thyroxine hormone, thyroxine is transferred across placenta, placental deiodinase convert Thyroxine to Triodothyronine. Thus thyroxin is needed for growth, brain, lung development. ${ }^{6}$

In normal pregnancy due to suppressive effect of increasing thyroxin and increased TSH secretion, thus TSH is kept at lowest possible normal range. Normal TSH levels according to trimester are as follows- 1st trimester -0.1 to $2.5 \mathrm{mIU} / \mathrm{L}, 2^{\text {nd }}$ trimester -0.2 to 3.0 $\mathrm{mIU} / \mathrm{L}, 3^{\text {rd }}$ trimester -0.3 to $3.0 \mathrm{mIU} / \mathrm{L}^{7}$

Kharab $\mathrm{S}$ et al studied correlation of thyroid functions with severity of pre-eclampsia and concluded that state of biochemical hypothyroidism which correlates with severity of pre-eclampsia and influences obstetric outcome. $^{8}$ In present study $13.3 \%$ had pre-eclampsia, of which $8 \%$ were mild pre-eclampsia and $5.3 \%$ were severe pre-eclampsia. Hypothyroidism is one of the cause of reversible hypertension, by causing vascular smooth muscle contraction of systemic and renal blood vessels, thereby increasing peripheral vascular resistance. Also, hypothyroidism causes increase in soluble forms like tyrosine kinase 1 which is antiangiogenic thus causing pre-eclampsia. ${ }^{9}$

Wang $\mathrm{S}$ et al concluded that significant correlation between clinical and subclinical hypothyroidism and risk of preterm birth. ${ }^{10}$ In this study $16.6 \%$ patients had preterm birth. Rao VR et al studied prevalence of 
hypothyroidism in recurrent pregnancy loss in $1^{\text {st }}$ trimester and concluded $4.12 \%$ women with RPL had hypothyroidism, in present study $21.3 \%$ had previous history of $1^{\text {st }}$ trimester abortions. ${ }^{11}$ Pregnancy is an inflammatory process involving shift in regulation of cytokine networks within local placental decidual environment. Dysregulation of local inflammatory processes can be associated with abortions and preterm labor. Thyroid hormones can directly influence angiogenic growth factor, cytokine production as well as trophoblast proliferation, survival and invasion. ${ }^{12-14}$ Thus presence of thyroid autoantibodies can cause dysregulated activity of immune system at fetal- maternal interface causing abortions and preterm labour. ${ }^{15}$

Ruchi Kishore et al studied about fetal outcome in hypothyroid women and concluded that $6.2 \%$ were IUD and $13 \%$ were IUGR in hypothyroid patients. ${ }^{16}$ In present study, fetal outcome was; IUGR $3.3 \%$ and $1.3 \%$ cases of IUD. Das Bishnu Prasad et al studied relationship of Gestational diabetes mellitus and Hypothyroidism in pregnancy. ${ }^{17}$ Hypothyroidism causes negative affect on glucose homeostasis by inducing insulin resistance, pregnant women with hypothyroidism had further amplified insulin resistance. In present study $3 \%$ of patients had gestational diabetes mellitus.

\section{CONCLUSION}

Hypothyroid patients present with various complications during pregnancy and these Complications are complex and serious, with a significant increase in maternal morbidity, and perinatal mortality. So, to identify these potential or overt hypothyroid patient thyroid screening is a must during pregnancy. T3, T4, TSH levels should be done during prenatal period, at first booking, thereafter at 8 weeks interval during pregnancy. TSH should be kept less than $2 \mathrm{mIU} / \mathrm{L}$ for adequate control.

Funding: No funding sources

Conflict of interest: None declared

Ethical approval: The study was approved by the Institutional Ethics Committee

\section{REFERENCES}

1. Mishra R. Ian Donald's practical obstetric problems. 7th ed. Priority books (springfield, VA, U.S.A.);2013.

2. Haddow JE, Palomaki GE, Allan WC, Williams JR, Knight GJ, Gagnon $\mathrm{J}$ et al. Maternal thyroid deficiency during pregnancy and subsequent neuropsychological development of the child. New Engl J Med. 1999;341(8):549-55.

3. Burrow GN. Thyroid function and hyperfunction during gestation. Endocrine Rev. 1993;14(2):194202.

4. Nambiar V, Jagtap VS, Sarathi V, Lila AR, Kamalanathan S, Bandgar TR et al. Prevalence and impact of thyroid disorders on maternal outcome in Asian-Indian pregnant women. J Thyroid Res. 2011;2011.

5. Stirrat GM. Aids to Obstetrics and Gynaecology for MRCOG. London: Churchill Livingstone;1983:87.

6. Lazarous JH. Thyroid function between 11-16 weeks of gestation- A critical time for fetal development. $13^{\text {th }}$ International Thyroid Congress Commercial Exhibition 2005. Poster Abstract no. 219.

7. Speroff L, Fritz MA, editors. Clinical gynecologic endocrinology and infertility. $7^{\text {th }}$ ed. lippincott Williams \& wilkins;2005.

8. Kharb S, Sardana D, Nanda S. Correlation of thyroid functions with severity and outcome of pregnancy. Ann Med Health Sci Res. 2013;3(1):43-6.

9. Levine RJ, Vatten LJ, Horowitz GL, Qian C, Romundstad PR, Kai FY et al. Pre eclampsia, soluble fms like tyrosine kinase 1 and risk of reduced thyroid function. BMJ. 2009;339:b4336.

10. Wang S, Li M, Chu D, Liang L, Zhao X, Zhang J. Clinical or subclinical hypothyroidism and thyroid autoantibody before 20 weeks pregnancy and risk of preterm birth: a systematic review. Zhonghua Fu Chan Ke Za Zhi. 2014;49:816-22.

11. Rao V, Lakshmi A, Sadhnani M. Prevalence of hypothyroidism in recurrent pregnancy loss in first trimester. Indian J Med Sci. 2008;62(9):359-63.

12. Colin IM, Isaac J, Dupret P. Functional lymphocyte subset assessment of Th1/Th2 profile in patients with autoimmune thyroditis by flow cytometric analysis of peripheral lymphocyte. J Biol Regul Homeost Agents. 2004;18:72-6.

13. Redman CW, Sargent IL. Latest advances in understanding pre eclampsia. Science. 2005;308:1592-6.

14. Challis JR, Lockwood CJ, Myatt L, Norman JE, Strauss III JF, Petraglia F. Inflammation and pregnancy. Reprod Sci. 2009;16:206-15.

15. Kishore R, Mishra N, Yadav J. Hypothyroidism in pregnancy and its impact on maternal and fetal outcome. J Evol Med Dental Sci. 2015;4(79)1384955.

16. Barber KJ, Franklyn JA, McCabe CJ, Khanim FL, Bulmer JN, Whitley GS et al. The invitro effects of triiodothyronine on epidermal growth factor- induced trophoblast function. J Clin Endocrinol Metab. 2005;90:1655-61.

17. Prasad DB, Nabanita D, Swagata B. Relationship of gestational diabetes mellitus with hypothyroidism in pregnancy. Sch J App Med Sci. 2015;3(7D):2719-23.

Cite this article as: Sapna IS, Mehazeena Z. Fetal Prevalence and outcome of hypothyroidism in women attending antenatal clinic at J. J. M Medical College. Int J Reprod Contracept Obstet Gynecol 2017;6:3537-9. 